\section{Da política e do esporte: a bandeira brasileira e as rupturas discursivas da identidade nacional}

On politics and sport: the Brazilian flag and the discursive ruptures of national identity

Jacyane Dantas SOUSA (UFPB) jacyanedantas11@gmail.com

Amanda Batista BRAGA (UFPB) braga.ufpb@hotmail.com

Recebido em: 29 de jul. de 2020. Aceito em: 03 de nov. de 2020.

\title{
00000000000
}

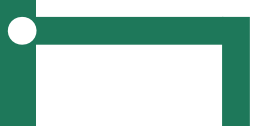

SOUSA, Jacyane Dantas; BRAGA,

Amanda Batista. Da política e do

esporte: a bandeira brasileira e as

rupturas discursivas da identidade

nacional. Entrepalavras, Fortaleza,

v. 11, n. 2, e2011, p. 1-21, maio-

ago./2021. DOI: 10.22168/2237-632122011.

Resumo: $O$ artigo tem por objetivo problematizar a bandeira brasileira enquanto enunciado que narra uma identidade cultural nacional na mesma medida em que, mediante seu trânsito entre o cenário político e o cenário esportivo, apresenta-se enquanto signo de sua ruptura. Para tanto, retoma-se a espessura histórica da bandeira brasileira e, partindo das jornadas de junho, de 2013, analisam-se enunciados que emergem em torno do processo de impeachment da então Presidenta da República, em 2016, e da profunda polarização política instaurada mediante as eleições presidenciais de 2018. Para concluir, faz-se ainda uma breve explanação de enunciados mais recentes, de 2019 e de 2020. Como perspectiva teóricometodológica, este artigo ancora-se nos Estudos Culturais, a fim de discutir os símbolos culturais que sustentam as identidades nacionais, em diálogo com a Análise do Discurso foucaultiana, a partir da qual se adota o método arqueológico para análise dos enunciados.

Palavras-chave: Discurso. Identidade. Bandeira. 
V. $11(2)$

1-21

maio-ago

2021

Abstract: This paper aims to problematize the Brazilian flag as a statement that narrates a national cultural identity to the same extent that, through its transit between the political scenario and the sports scenario, it presents itself as a sign of its rupture. To this end, the historical importance of the Brazilian flag is recaptured, and, starting from the June journeys, in 2013, we analyze statements that emerge around the impeachment process of 2016 and the deep political polarization that occurred through the presidential elections of 2018. To wrap it up, a brief explanation of the most recent statements from 2019 and 2020 is also made. As a theoretical-methodological perspective, this paper is anchored in Cultural Studies, to discuss the cultural symbols that support national identities, in dialogue with Foucaultian Discourse Analysis, from which the archaeological method for the analysis of statements is adopted.

Keywords: Discourse. Identity. Flag.

\section{Introdução}

Este artigo parte da ideia segundo a qual "Uma cultura nacional é um discurso - um modo de construir sentidos que influencia e organiza tanto nossas ações quanto as concepção que temos de nós mesmos" (HALL, 2006, p. 50). Mais do que isto: parte da concepção de que esta cultura nacional é produzida a partir de narrativas de uma comunidade simbólica, que agenciam a conservação dos dizeres sobre as glórias e os reveses que constituem a nação, quais sejam, sua origem, seu povo, suas tradições. Trata-se, assim, de pensar a cultura nacional a partir dos símbolos e das representações que a instituem enquanto discurso e, do mesmo modo, dos sentidos que tais símbolos produzem nas descontinuidades instauradas pela história.

Mais particularmente, este artigo se apresenta com o objetivo de problematizar a bandeira brasileira enquanto enunciado que narra uma comunidade simbólica na mesma medida em que, mediante seu trânsito entre o cenário político e o cenário esportivo, apresentase enquanto signo de sua ruptura. O intuito é retomar a espessura histórica da bandeira brasileira para, na sequência, empreender uma análise enunciativa que traça um breve percurso, a partir do qual se realçam as rupturas que se pretende demonstrar. Parte-se das jornadas de junho, em 2013, para analisar: i) enunciados que emergem do embate gerado em torno do processo de impeachment aberto contra Dilma Rousseff, a então Presidenta da República, em 2016; ii) enunciados que emergem da profunda polarização política instaurada mediante as eleições presidenciais, das quais Jair Bolsonaro saiu vitorioso, em 2018; iii) e finaliza-se com uma breve explanação de algumas emergências mais recentes, como o discurso subjacente ao pronunciamento de Jair Bolsonaro no dia da sua posse, e o vídeo da campanha Devolvam minha 
bandeira, lançado em julho de 2020. O que interessa, em cada um desses momentos, é analisar o funcionamento discursivo da bandeira brasileira enquanto símbolo de uma identidade nacional, que se desloca mediante sua apropriação por determinados grupos.

Como perspectiva teórico-metodológica, este artigo ancora-se nos Estudos Culturais em diálogo com a Análise do Discurso foucaultiana. Dos estudos culturais, com Hall (2006), Bauman (2005) e Sousa Santos (1993), interessa-nos discutir as identidades culturais nacionais, bem como os símbolos que as sustentam enquanto discurso e as repercutem indefinidamente. Com a Análise do Discurso, particularmente aquela que encontra em Michel Foucault (2010a; 2010b) seus principais pressupostos, interessa-nos a proposição de um método arqueológico a partir do qual se interroga a materialidade discursiva a respeito de suas condições históricas de emergência e se questiona as relações que os enunciados estabelecem entre si, bem como a função enunciativa que neles se exerce.

\section{Identidades culturais e discurso}

As discussões em torno dos sujeitos e das identidades culturais na pós-modernidade não emergem como simples contraponto às concepções que as antecedem, mas como índice de uma quebra, de uma ruptura que se dá a ver no interior mesmo das concepções de sujeito então estabilizadas na teoria social: tanto do sujeito iluminista quanto do sujeito sociológico, conforme Hall (2006, p. 11). É a despeito das identidades formadas por um centro essencial, bem como das identidades produzidas na interação social, que os sujeitos e as identidades pós-modernas agenciam a perda de um "sentido de si", um descentramento do sujeito que suspende a concepção que temos de nós mesmos enquanto sujeitos integrados. Com isso, as ideias de pertencimento e de identidade, a partir do final do século XX, tornamse absolutamente revogáveis. Mesmo as identidades que, a princípio, possam aparentar qualquer solidez, escondem "negociações de sentido, jogos de polissemia, choques de temporalidades em constante processo de transformação", nas palavras de Sousa Santos (1993, p. 31).

As identidades culturais nacionais não estão fora dessa dinâmica, conforme se pretende demonstrar, embora atuem ainda como um forte dispositivo discursivo que comporta a diferença como identidade. A identificação que, no interior das sociedades mais 
V. $11(2)$

1-21

maio-ago

2021

tradicionais, direcionava-se à tribo, à religião, à região, produziram, paulatinamente, uma dada lealdade àquilo que Hall (2006, p. 49) entende como o "teto político do Estado-nação": uma produção discursiva que agencia sentidos sobre a nação e constrói identidades na medida em que os sujeitos aí se identificam. Tais sentidos são instituídos a partir de narrativas simbólicas que trabalham na manutenção dos dizeres sobre o povo, sobre a origem e sobre as tradições da nação. São exemplos disso: i) a narrativa da nação, para a qual concorrem a mídia, a literatura, a cultura popular, na oferta das estórias e dos símbolos que narram as glórias e os reveses que constituem a nação; ii) a ênfase nas origens e na tradição, que soam intrínsecas ao caráter nacional, a despeito das vicissitudes da história; iii) a própria invenção das tradições, enquanto prática discursiva que pretende ecoar, indefinidamente, um passado conveniente; iv) o mito fundacional, como narrativa que marca uma dada origem para a nação e para o povo; v) e a ideia de um povo puro, original, ainda que, no processo de desenvolvimento nacional, esses grupos não tenham efetiva participação (HALL, 2006).

Assim, a identidade nacional, bem como qualquer discurso produzido no interior das relações de poder, não é naturalmente construída e internalizada pelos sujeitos desde o nascimento, de modo instintivo. Ela é estrategicamente agenciada pelo Estado, que passa a funcionar como dispositivo de controle dos sujeitos na medida em que faz uso da identidade nacional para legitimar a obediência de seus indivíduos, tão plurais em suas identificações quanto singulares aos olhos das narrativas nacionais. É assim que a fábula do nascimento passa a exercer uma coerção que exige adesão e fidelidade à ideia de nação: um direito monopolista sustentado no limite entre o "nós" e os "outros" que faz despertar, nos sujeitos, um sentimento de lealdade.

Suspenso, portanto, o caráter natural que a construção histórica das identidades nacionais poderia sugerir, seria preciso pensá-las como um dispositivo que conforma a diferença em unidade através do exercício de diferentes formas de coerção. É nesse sentido que se propõe aproximar as discussões acerca das identidades culturais daquelas formuladas por Michel Foucault sobre o discurso, partindo do pressuposto de que "o discurso é o conjunto das significações coercitivas e constrangedoras que perpassam as relações sociais" (FOUCAULT, 2001, p. 123). Com isso, analisar o discurso não é somente analisar um conjunto de coisas ditas, mas assumir também o não-dito, ou ainda aquilo que está materializado em gestos, atitudes, modos de existência 
e esquemas de comportamento. Trata-se de analisar aquilo que perpassa nossas identificações, nossas condutas. E numa perspectiva arqueológica, trata-se de encampar esse projeto a partir das condições de emergência dos enunciados e da relação estabelecida entre eles nas descontinuidades da história.

Para Foucault (2010a), o método arqueológico caracterizase por empreender a descrição de um arquivo, cuja conceituação não está relacionada ao amontoado de textos produzidos por uma dada sociedade, num determinado momento histórico, a partir do qual se poderia acessar seu passado ou sua identidade. Trata-se, ao contrário, daquilo que faz com que esse mesmo amontoado de textos, ou mesmo tudo aquilo que foi simplesmente produzido por tantos de nós, não tenha nascido ao acaso, "segundo as leis do pensamento, ou apenas segundo o jogo das circunstâncias", diria Foucault (2010a, p. 146), mas segundo as regularidades e rupturas mantidas entre os discursos imersos na história. Assim, para Foucault (2010a, p. 147), o arquivo é "a lei do que pode ser dito, o sistema que rege o aparecimento dos enunciados como acontecimentos singulares", e seu funcionamento deve determinar as formas de dizibilidade, de conservação, de memória, de reativação e de apropriação dos discursos em uma dada época e em uma determinada cultura (FOUCAULT, 2010b, p. 10).

Com as formas de dizibilidade, questiona-se: "de que é possível falar? O que foi constituído como domínio do discurso?". Na sequência, naquilo que diz respeito às formas de conservação, aos discursos que encontraram condições de emergência, interroga-se: "quais são os enunciados destinados a passar sem vestígio? Quais os que são destinados, ao contrário, a entrar na memória dos homens?". Com as formas de memória, parte-se dos discursos destinados a serem memorizados para indagar: "que tipo de relações são estabelecidas entre os sistemas dos enunciados presentes e o corpus dos enunciados passados?". A estes enunciados presentes, em suas diversas relações, as formas de reativação questionam: "entre os discursos das épocas anteriores ou das culturas estrangeiras, quais são os que retemos, que valorizamos, que importamos, que tentamos reconstituir?". E, por fim, aos enunciados reativados, as formas de apropriação interrogam: "quais indivíduos, quais grupos, quais classes têm acesso a tal tipo de discurso?" (FOUCAULT, 2010b, p. 10).

Desse modo, a proposta foucaultiana de uma arqueologia dos discursos concerne à descrição de um arquivo e dos jogos de 
V. $11(2)$

1-21

maio-ago

2021

memória que aí funcionam, considerando as leis de possibilidades que oferecem condições de emergência aos enunciados e o modo como eles são posteriormente deslocados e atualizados no interior das séries enunciativas às quais se integram, haja vista que "Não há enunciado que não suponha outros; não há nenhum que não tenha, em torno de si, um campo de coexistências, efeitos de série e de sucessão" (FOUCAULT, 2010a, p. 112). Isso significa pressupor que, uma vez dito, o enunciado se abre a um campo de memória e se oferece "à repetição, à transformação, à reativação" (FOUCAULT, 2010a, p. 32), o que exige uma reflexão acerca não apenas de sua manifestação, mas também de suas continuidades e descontinuidades na dispersão do tempo histórico.

Assim, às coisas ditas, cabe questionar o campo de elementos antecedentes a partir dos quais se situam, bem como as relações que promovem seu deslocamento e sua atualização, uma vez que a sucessão dos enunciados não se reduz a um simples amontoado de dizeres ou mesmo a uma justaposição de elementos. Delata, ao contrário, o próprio funcionamento do arquivo, fazendo "aparecerem as regras de uma prática que permite aos enunciados subsistirem e, ao mesmo tempo, se modificarem regularmente". O arquivo é, assim, o próprio "sistema geral da formação e da transformação dos enunciados" (FOUCAULT, 2010a, p. 147-148). Não por acaso, é a partir dessa perspectiva que propomos retomar a espessura histórica da bandeira brasileira para analisar seu atual trânsito entre os cenários político e esportivo, delatando as regularidades e rupturas que se dão a ver em um percurso que compreende, com Foucault (2010b), as formas de dizibilidade, de conservação, de memória, de reativação e de apropriação dos enunciados que a discursivizam.

\section{Da política ao esporte: dizibilidade, conservação e memória da bandeira brasileira}

As bandeiras nacionais são elementos que se inserem naquilo que Hall (2006) entendeu como sendo uma narrativa da nação. Elas sintetizam, representam e dão sentido às experiências, aos triunfos e às derrocadas que caracterizam coletivamente a nacionalidade. Trata-se do símbolo de uma "comunidade imaginada", ou mesmo de uma "tradição inventada" que conecta a vida do cidadão comum ao destino de seu país. No que se refere especificamente à bandeira brasileira, interessanos, neste tópico, demonstrar suas formas de dizibilidade, suas formas de conservação e suas formas de memória. 
A produção da bandeira brasileira se inscreve em uma rede de enunciados que estavam já consolidados como nacionalistas na tentativa de se apresentar enquanto continuidade de um passado triunfante. Não é por acaso, portanto, que as cores da bandeira tenham sido expressamente mencionadas no Decreto $n^{0}$ 4, publicado em 19 de novembro de 1889 (BRASIL, 1889), que Estabelece os distinctivos da bandeira e das armas nacionaes, e dos sellos e sinetes da Republica:

O Governo Provisorio da Republica dos Estados Unidos do Brazil: Considerando que as côres da nossa antiga bandeira recordam as luctas e as victorias gloriosas do exercito e da armada na defesa da patria; Considerando, pois, que essa côres, independentemente da forma de governo, symbolisam a perpetuidade e integridade da patria entre as outras nações; Decreta: Art. $1^{\circ}$. A bandeira adoptada pela Republica mantem a tradição das antigas côres nacionaes - verde e amarela [...]. (BRASIL, 1889)

A bandeira nacional, tal como hoje a conhecemos, foi oficialmente apresentada em 1889, apenas alguns dias após a Proclamação da República. Nesse decreto, é a legislação do Estado que trabalha na manutenção e na propagação da identidade nacional mediante as narrativas que, amparadas pelas cores da bandeira, "recordam as luctas e as victorias gloriosas do exercito e da armada na defesa da patria" (BRASIL, 1889). São as cores da bandeira que, ainda segundo o Decreto, "symbolisam a perpetuidade e integridade da patria entre as outras nações" (BRASIL, 1889). Não se trata de outra coisa, portanto, senão da produção das tradições e da narrativa do Brasil enquanto nação integrada, cuja história se consolidaria com a retomada de um passado glorioso, instituindo-o "grande" no presente e, quiçá, no futuro, materializados, como visto, pelo verde e amarelo. Mas, esse acontecimento discursivo - de instituição da atual bandeira brasileira não constitui suas formas de dizibilidade, uma vez que ela já havia sido enunciada, anteriormente, enquanto domínio do discurso.

As cores e as formas da bandeira brasileira guardam, em seu bojo, o projeto do estandarte imperial, do qual promoveu apenas a retirada das armas do Império e a inclusão do emblema republicano. Esse estandarte - apresentado em Decreto de dezembro de 1822 inscreve-se, por sua vez, à esteira da bandeira do Reino do Brasil, da qual substituiu a coroa real pela coroa imperial. Com isso, têm-se os elementos reprimidos pelas formas de conservação da atual bandeira brasileira (as armas do Império e a coroa Real) e, do mesmo modo, sua forma de dizibilidade com a bandeira do Reino de Brasil. 
V. $11(2)$

1-21

maio-ago

2021

É a bandeira do Reino do Brasil, portanto, instituída em setembro de 1822, que inaugura as cores e as formas geométricas da bandeira brasileira tal como hoje a conhecemos, as quais teriam sido, segundo Luz (2005), um projeto idealizado pelo Príncipe Regente D. Pedro I e apresentado em dois Decretos de 18 de setembro de 1822. Com o primeiro Decreto, afirma-se que "O Laço ou Tope Nacional Braziliense, será composto das côres emblemáticas - Verde de primavera, e amarelo de ouro" (BRASIL, 1822a); com o segundo Decreto, determina-se que "Será d'ora em diante o Escudo deste Reino do Brasil, em campo verde huma esphera Armilar de ouro atravessada por uma Cruz da Ordem de Christo" (BRASIL, 1822b), assegurando-se, ainda, a presença dos ramos de café e tabaco como representantes de suas riquezas.

Assim, não apenas as bandeiras inscrevem-se em um a priori histórico - aqui entendido, à maneira de Foucault (2010a, p. 144), como uma "condição de realidade para os enunciados" -, mas também os próprios Decretos, que materializam linguisticamente a espessura histórica das cores que reconhecemos como nossas: "verde de primavera, amarelo de ouro". Trata-se, mais uma vez, da invenção das tradições de que fala Hall (2006), cujas narrativas fornecem elementos que têm por função promover uma identificação dos indivíduos em torno dos mesmos símbolos, numa conformação da dispersão dos corpos. Nesse sentido, a bandeira nacional, arrolada como um desses símbolos, funciona como dispositivo de controle das populações em torno do Estado. A contínua utilização desses símbolos faz com que haja um sentimento de servidão aos interesses de toda uma comunidade, viabilizando o discurso do civismo e do empenho coletivo em prol do bem do país. É isso que explica o recorrente uso da bandeira e das cores nacionais nos governos autoritários.

No período do Estado Novo (1930 - 1940), por exemplo, durante o qual Estado e nação constituíam, juntos, uma base política unificada, o poder do discurso nacionalista se dá a ver na queima das bandeiras estaduais, em 1937, em benefício do culto exclusivo à bandeira nacional, conforme Guedes e Silva (2019). Já durante o regime militar (1964 - 1985), em sua busca por legitimação político-ideológica em cujo mote residia o combate ao comunismo e a publicização, o mais massificada possível, dos índices de crescimento econômico, é ainda nos símbolos e nas cores nacionais que se dá a promoção do sentimento patriótico, do qual se acreditava decorrer certa naturalização, por parte da população, do discurso nacionalista, bem como o sacrifício de todos 
em nome da construção de um "grande" país. É aqui que residem as formas de memória da bandeira nacional, na medida em que se faz incidir o corpus de enunciados passados com aqueles que então viriam, naquele momento, a emergir e a se popularizar, conforme veremos.

É durante o regime militar que se dá a publicação da Lei no 5.700, de 01 de setembro de 1971 (BRASIL, 1971), que dispõe sobre a apresentação dos símbolos nacionais: a bandeira, o hino, as armas e o selo. No que se refere especificamente à bandeira, apesar de instituir, em seu Art. 10, que "A Bandeira Nacional pode ser usada em tôdas as manifestações do sentimento patriótico dos brasileiros, de caráter oficial ou particular" (BRASIL, 1971), a referida Lei institui também toda uma regulação para seu uso: sua forma de apresentação, sua forma de armazenamento, suas dimensões, o estilo a ser empregado em sua saudação e, finalmente, a obrigatoriedade de seu fomento enquanto símbolo nacional nos estabelecimentos de ensino. Essa regulação, simultaneamente às práticas discursivas que pretendiam naturalizar um reconhecimento identitário e, portanto, um pertencimento, constitui um paradoxo: apresenta-se um discurso segundo o qual a bandeira pertence ao povo brasileiro na mesma medida em que regula seu uso, conforme Guedes e Silva (2019).

Nesse cenário, é a seleção brasileira de futebol que, paulatinamente, populariza a bandeira enquanto símbolo pátrio e faz com que o próprio povo passe a se apropriar de suas cores, além do Estado, das elites e dos militares. Ainda segundo Guedes e Silva (2019), é o triunfo do tricampeonato mundial de futebol, na década de 70, que marca, mais fortemente, a emergência do orgulho nacional materializado, agora, não apenas nas cores - verde e amarelo -, mas também na camisa da seleção como metonímia da bandeira. A bandeira, como símbolo, anteriormente restrita aos palacetes e aos quartéis, ganha não apenas as ruas, mas também o mercado, na produção de uma infinidade de artefatos a partir dos quais seria estilizada, adaptada, modificada. A bandeira brasileira encontra, definitivamente, suas formas de memória, efetivando sua espessura histórica e sua então emergência: o povo toma para si as cores e a própria bandeira nacional, numa representação material da narrativa da nação brasileira, sua "comunidade imaginada". 
V. $11(2)$

1-21 maio-ago 2021

\section{Do esporte à política: reativação e apropriação da bandeira brasileira}

Demonstramos, em tópico anterior: i) a dizibilidade da forma e das cores da bandeira nacional por meio da bandeira do Reino de Brasil enquanto domínio do discurso, em 1822; ii) sua conservação não apenas no estandarte imperial, mas ainda na bandeira brasileira tal qual hoje a conhecemos, em 1889; iii) além de sua memorização enquanto discurso, materializado em sua popularização na década de 70. Resta-nos, agora, mediante uma análise enunciativa, analisar as formas de reativação e de apropriação pelas quais passam a bandeira nacional atualmente.

De início, seria preciso atestar que o intenso uso da bandeira (e, metonimicamente, da camisa da seleção brasileira), cuja emergência no campo esportivo permaneceu regular até a primeira década dos anos 2000, passa a protagonizar momentos decisivos na história política do país entre 2013 e 2014. No que se refere a 2013, as mobilizações organizadas pelo MPL (Movimento Passe Livre), conhecidas como as jornadas de junho, apresentaram-se como uma contestação que recorria aos símbolos pátrios como instrumento de legitimidade e do próprio apoderamento, por parte do povo, dos mecanismos do Estado. Era a bandeira brasileira que sustentava a ideia do povo em torno e no comando do país. Em 2014, com os protestos contrários à realização da Copa do Mundo de Futebol no Brasil, a "festa cívica" encampava os símbolos pátrios na mesma medida em que promovia uma ruptura com o campo esportivo que os havia popularizado - Não vai ter copa ${ }^{1}$. Para Pinto (2017, p. 119), os movimentos de 2013 e 2014 apontam para "um deslocamento discursivo em uma direção conservadora", em detrimento do discurso progressista que tomava as ruas desde a redemocratização.

Comprovam esse deslocamento os episódios em que Dilma Rousseff (PT), então Presidenta da República, fora hostilizada na abertura e no encerramento da Copa do Mundo de Futebol, em 2014. Naquele momento, a significativa polarização política que vinha sendo construída desde as manifestações de 2013, e que então tomava conta do país, aprofundava e tornava cada vez mais visível o "sequestro" para usar a expressão adotada por Guedes e Silva (2019) - das cores e da bandeira nacional pelos partidos conservadores. Isso significa que esses símbolos não apenas migraram do campo esportivo ao campo político,

${ }^{1}$ Quem grita "não vai ter Copa" nas manifestações? Disponível em: https://congressoemfoco.uol.com.br/especial/noticias/quem-grita-nao-vai-ter-copa/. Acesso em: 22 jul. 2020. 
como também foram apropriados por alguns grupos. Não por acaso, apenas três meses depois de sua posse, em março de 2015, o verde e amarelo volta às ruas para exigir o impeachment de Dilma Rousseff.

Para analisar mais atentamente esses discursos, além do modo como é reativada e apropriada, nesse momento, a bandeira nacional, selecionamos alguns enunciados produzidos por movimentos de grande mobilização popular - como o Vem pra rua, o Movimento Brasil Livre (MBL) e a Frente Brasil Popular - entre os anos de 2016 e 2018. São enunciados publicados e amplamente difundidos nos perfis oficiais desses momentos no Facebook. O primeiro deles, abaixo, é uma convocação feita pelo movimento Vem pra rua em 10 de abril $2016^{2}$.

Figura 1 - Vem pra rua 2016

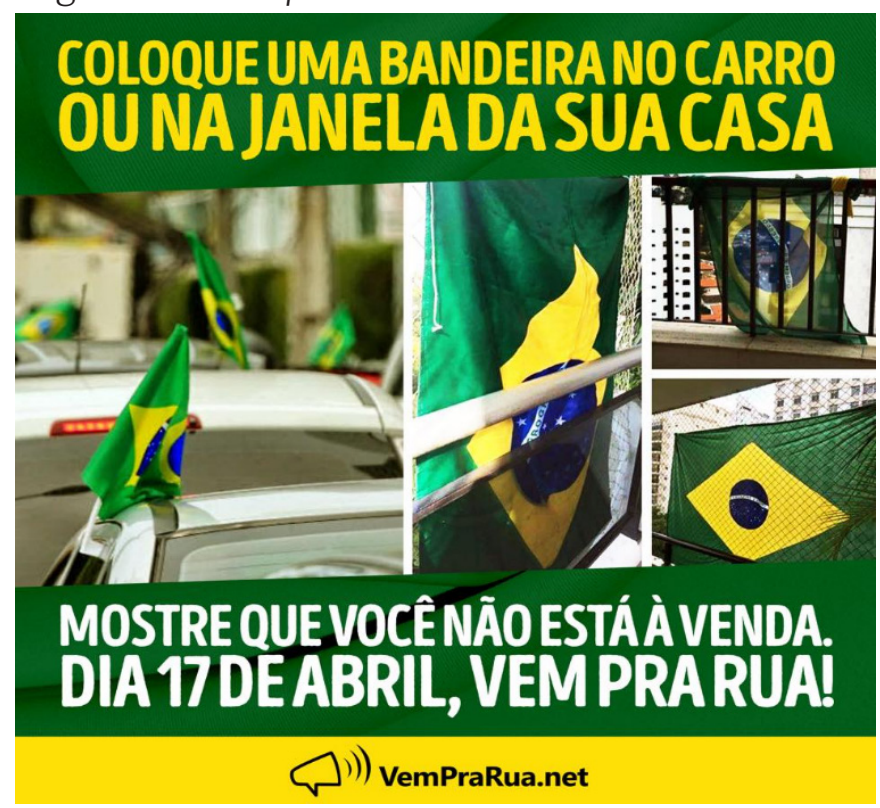

Fonte: Facebook Vem pra rua.

Na publicação, a imagem é acompanhada da seguinte legenda:

O Vem Pra Rua convoca todos para uma campanha. É fácil participar. Nesta semana e até domingo, quando será a votação do impeachment, vamos colorir o Brasil de verde e amarelo! Coloque uma bandeira na janela de sua casa, uma fitinha no seu carro, um tecido verde no jardim do seu prédio. Ou cole um papel nessas cores no vidro do carro. Não importa o tamanho, o que importa é que nossas cidades fiquem das cores da nossa bandeira, do nosso país. Vamos mostrar aos deputados indecisos e contrários ao impeachment a nossa força e união. Juntos, somos muitos! 
V. $11(2)$

1-21

maio-ago

2021

Esse enunciado, produzido na semana anterior à votação do impeachment na Câmara dos Deputados, solicita à população que "coloque uma bandeira no carro ou na janela de casa", a fim de mostrar que a população "não está à venda". Trata-se, aqui, da tentativa de reativar a popularização da bandeira brasileira, bem como de suas cores, que havia sido promovida na década de 70 no decorrer do regime militar em torno do tricampeonato de futebol. Por um lado, imageticamente, apresenta-se a bandeira em distintos cenários, particularmente em carros e em varandas de apartamentos, incentivando sua pulverização pela cidade. Por outro lado, linguisticamente, alude-se às diversas alternativas que, ainda que abram mão da bandeira, não abrem mão das cores consideradas representativas da identidade nacional: sugerese uma "fitinha" no carro, um "tecido verde" no jardim do prédio, ou mesmo um "papel nessas cores" no vidro do carro. Segundo a legenda: "Não importa o tamanho, o que importa é que nossas cidades fiquem das cores da nossa bandeira, do nosso país".

O efeito de sentido se constrói na medida em que o enunciado faz uso da espessura histórica da bandeira e do verde e amarelo enquanto símbolos nacionais para sugerir não apenas uma postura política uníssona da população brasileira em torno do impeachment, mas principalmente a apoderação, por parte dessa mesma população - supostamente coesa -, dos rumos do país. Não é aleatório, portanto, o repetido uso de pronomes possessivos no recorte acima apresentado: "nossas cidades", "nossa bandeira", "nosso país". O objetivo era pressionar os deputados indecisos mediante uma mudança na paisagem urbana que pudesse produzir um efeito de coletividade, de modo que, uma vez contrários ao impeachment, os deputados seriam contrários ao próprio Brasil. Assim, o que o enunciado delata é a apropriação dos símbolos pátrios por parte dos partidos conservadores na tentativa de fazer confundir sua ideologia político-partidária com os próprios traços da identidade nacional, apelando para o sentimento de pertencimento promovido por tais símbolos. Tal apropriação está posta, inclusive, nos lugares indicados para a manifestação patriótica, cuja descrição revela uma elite econômica: carros, varandas de apartamentos, jardins de prédios.

Nesse mesmo cenário, o enunciado 3 abaixo é publicado no perfil do movimento Frente Brasil Popular, mais especificamente em 28

3 Disponível em: https://www.facebook.com/FrenteBrasilPopular/posts/1761756637380461. Acesso em: 20 jun. 2020. 
de março de 2016, convocando apoiadores para a Jornada Nacional pela Democracia. Na legenda: "Traga a sua bandeira! Vem pra democracia!".

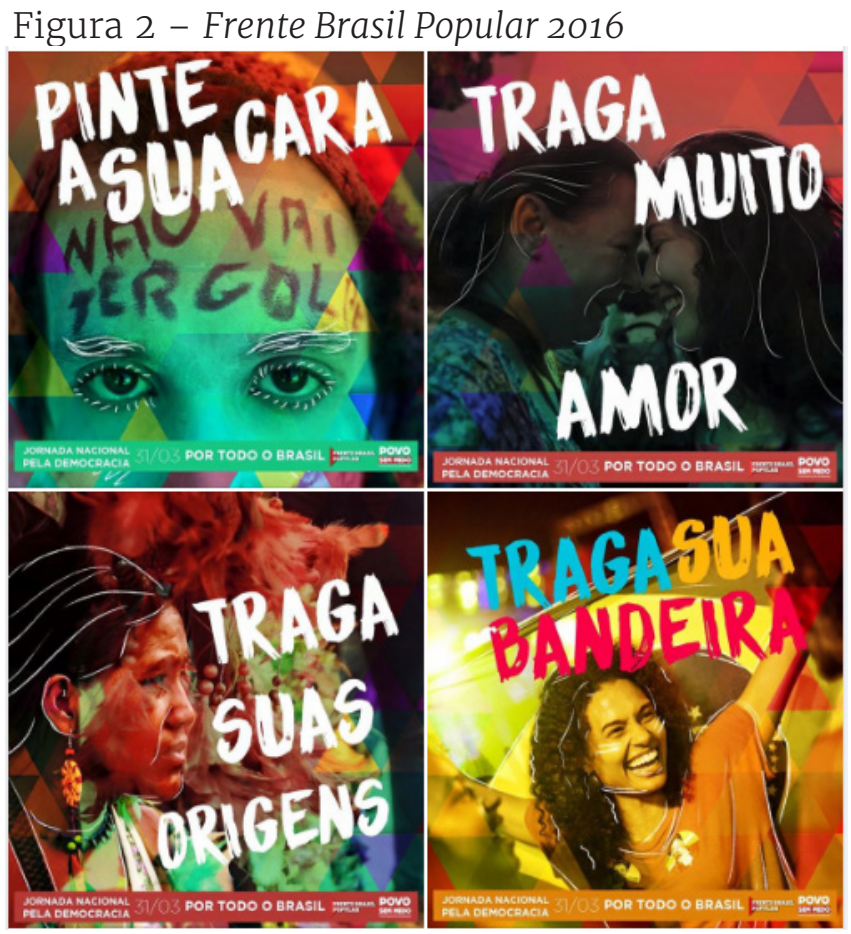

Fonte: Facebook Frente Brasil Popular.

O enunciado, composto por quatro fotografias manipuladas, retrata pelo menos 5 pessoas: i) o rosto de um jovem em cuja testa lêse a frase "não vai ter golpe", ao qual se sobrepõe a sentença "Pinte sua cara"; ii) duas mulheres que se olham em um gesto afetivo, de modo a sugerir que formam um casal lésbico, sobre o qual se escreve: "Traga muito amor"; iii) uma mulher indígena em um cenário caracterizado por adereços de pena, sobre os quais lê-se "Traga suas origens"; iv) e, por fim, uma mulher negra que veste uma camisa vermelha em uma paisagem urbana e que levanta, com as próprias mãos, a bandeira brasileira. Sobre esta última, a única frase escrita em letras coloridas: "Traga sua bandeira". Com esse conjunto, tem-se a população brasileira representada pela juventude, pela comunidade LGBTQIA+, pela população indígena e pela negritude. Assim, em contraposição à usurpação dos símbolos nacionais feita pela direita, o que a esquerda promove, como resposta, é uma subversão e, ao mesmo tempo, uma expansão do sentido da bandeira nacional. O próprio sintagma "bandeira", nesse enunciado, passa por um processo de ressignificação: a bandeira a que se faz referência, aqui, não é a bandeira verde e amarela, embora ela apareça materializada, mas as causas políticas identitárias. 
V. $11(2)$

1-21

maio-ago

2021

Por um lado, a direita: ancorada em uma concepção de identidade construída sob o "teto político do Estado-nação", abaixo do qual o Estado agencia uma coletividade em torno dos símbolos nacionais com os quais os sujeitos se identificam pela ideia de pertencimento. Por outro lado, a esquerda: ancorada, por seu turno, em uma concepção de identidade pós-moderna, em cujo bojo reside o apreço pela diferença e pela observação daquelas identidades a que Bauman (2005) chamou de sub-classe, isto é, "fora daquele conjunto no interior do qual as identidades (e assim também o direito a um lugar legítimo na totalidade) podem ser reivindicadas e, uma vez reivindicadas, supostamente respeitadas" (BAUMAN, 2005, p. 46). Assim, o que está expresso, nesse enunciado, é o respeito à pluralidade do povo brasileiro, para quem a bandeira não é apenas o símbolo nacional, mas a própria causa pela qual se luta.

De um lado, a bandeira homogeneizante e elitizada do movimento Vem pra rua; de outro, a bandeira pluralizada e inclusiva da Frente Brasil Popular. A ruptura discursiva em torno da identidade nacional - materializada por esse símbolo que, outrora, significava a "perpetuidade e integridade da patria", conforme Decreto de 1889 (BRASIL,1889) - seria confirmada, ainda, com a publicação, em Diário Oficial da União de 09 de julho de 2016, de um veto que proibia a projeção da bandeira nacional na fachada da Federação das Indústrias do Estado de São Paulo em datas não comemorativas ${ }^{4}$ A decisão, tomada pela Comissão de Proteção à Paisagem Urbana, alegava que a exibição feria a Lei Cidade Limpa por ser feita com cunho político. Um dos integrantes da Comissão explicou à época que "A bandeira pode ser colocada, mas se houver um contexto. Da maneira como está sendo usada é com cunho político" (ESTAÇÃO, 2016). Naquela ocasião, descortinava-se a utilização da bandeira nacional, inclusive na esfera legal, como símbolo de um grupo político restrito e não mais da coletividade nacional. A proibição gerou inúmeras críticas dos movimentos Vem pra rua e Movimento Brasil Livre, que alegaram se tratar de censura.

Dois anos depois, em 2018, a prisão do ex-Presidente Lula, as eleições presidenciais e a Copa do Mundo de Futebol fariam a bandeira nacional voltar ao centro do debate político e esportivo. Tanto o acontecimento discursivo da prisão de Lula no âmbito da operação Lava-Jato, quanto aquele da campanha cujo desfecho seria a eleição

\footnotetext{
4 Fiesp está proibida de exibir bandeira do Brasil em telão na avenida Paulista. Disponível em: https:// www.jornalestacao.com.br/2016/07/18/fiesp-esta-proibida-de-exibir-bandeira-do-brasilem-telao-na-avenida-paulista/. Acesso em: 20 jun. 2020.
} 
de Jair Bolsonaro, trabalharam na promoção de uma radicalização do processo de polarização política que havia se desenhado com as jornadas de junho e se consolidado com o processo de impeachment contra Dilma Rousseff. Nesse cenário, não só a bandeira, mas ainda a própria camisa da seleção de futebol, enquanto enunciado metonímico da bandeira brasileira e da própria identidade nacional - tal como vinha sendo construído desde 2016 - tornam-se um objeto de disputa. Um forte indicativo desse processo está na recriação da camisa da seleção de futebol, que renuncia ao verde e amarelo para ganhar o vermelho cor historicamente associada aos movimentos de contestação popular: "Com medo de vestir a amarelinha na Copa do Mundo e ser confundido com pato paneleiro? A gente resolveu esse problema" (O POVO ONLINE, 2018)5 , relatava a responsável pelo modelo. O próprio criador do mais conhecido uniforme da seleção, Aldyr Garcia Schlee, chega a declarar que "Queria que a seleção usasse uma cor completamente diferente da amarela, para que não me associem mais a ela" (PIRES, 2018) ${ }^{6}$.

É nesse cenário, no interior do qual se disputam e se ressignificam os enunciados que figuram enquanto símbolos nacionais, que, em 14 de junho de 2018, o movimento Vem pra rua publica, em seu perfil, o seguinte enunciado:

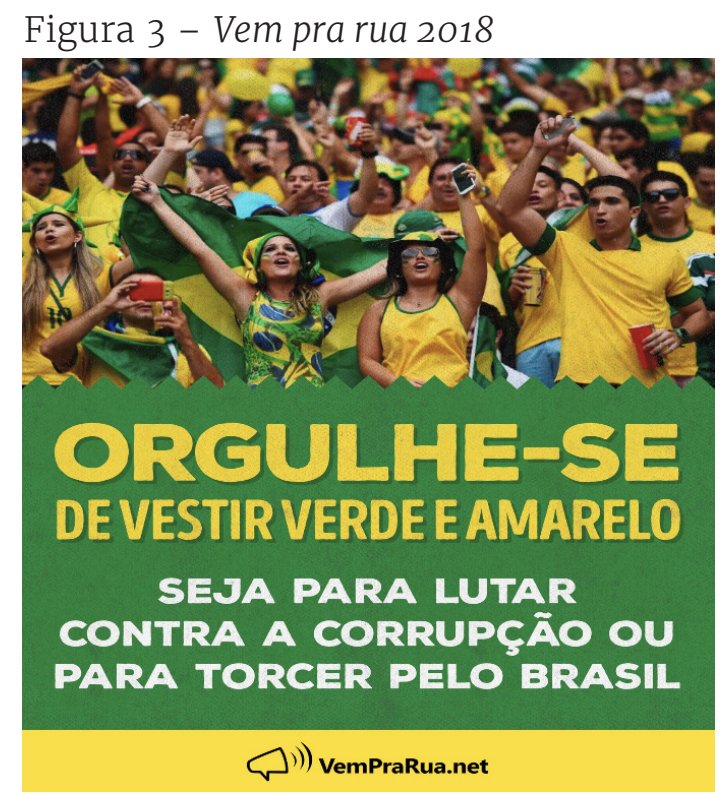

Fonte: Facebook Vem pra rua.

\footnotetext{
${ }^{5}$ Designer cria camisa vermelha da Seleção Brasileira para pessoas de esquerda. Disponível em: https://www.opovo.com.br/esportes/futebol/2018/04/designer-cria-camisa-vermelha-daselecao-brasileira-para-pessoas-de-es.html. Acesso em: 24 jul. 2020.

${ }^{6}$ Camisa da seleção, o símbolo contaminado por rixas ideológicas e as negociatas dos cartolas. Disponível em: https://brasil.elpais.com/brasil/2018/06/16/deportes/1529108134_704637.html. Acesso em: 20 jun. 2020.
} 
V. $11(2)$

1-21

maio-ago

2021

Composto quase exclusivamente pelo verde e amarelo, o enunciado ${ }^{7}$ retrata um conjunto de pessoas que, vestidas com camisas amarelas e exibindo a bandeira brasileira, vibram conjuntamente. Abaixo, a materialidade linguística recomenda: "Orgulhe-se de vestir verde e amarelo. Seja para lutar contra a corrupção ou para torcer pelo Brasil". O enunciado mantém, em seu domínio associado, um outro enunciado, qual seja: aquele produzido pela mesma organização, em 2016. Lá como cá, os verbos estão no imperativo ("coloque", "mostre", "orgulhe-se"), o mesmo imperativo que aparece no nome do movimento ("vem" pra rua). Lá como cá, está reativada a popularização da bandeira brasileira, bem como de suas cores, promovida a partir da década de 70 com o tricampeonato mundial de futebol. Lá como cá, está reativada a espessura histórica da bandeira e do verde e amarelo enquanto símbolos nacionais.

A tentativa, portanto, é a construção de uma regularidade que produz um efeito de sentido globalizante: aquele que imprime uma dada ideologia político-partidária à cena esportiva e à identidade nacional. É assim que, a despeito da oração alternativa construída pelo enunciado, tem-se que "torcer pelo Brasil" rapidamente se transforma em "lutar contra a corrupção", e ambas se transformam em "posicionar-se favoravelmente ao alinhamento ideológico às forças políticas conservadoras". É assim que a fotografia que compõe o enunciado faz confundir as ruas com os estádios: as torcidas esportivas com as manifestações populares.

o que o enunciado deseja produzir enquanto sentido é que a homogeneidade da torcida pela seleção brasileira de futebol - alcançada por ser a única representante do país nas competições do esporte - reside também na "torcida" política, que teria como única via possível o apoio à ideologia conservadora (representada, aqui, pela classe média branca que compõe a fotografia, em contraposição aos perfis apresentados pelo enunciado publicado pela Frente Brasil Popular, em março de 2016). Assim, entre o enunciado produzido em 2016 e este, produzido em 2018, o movimento Vem pra rua constrói a ideia de continuidade das manifestações que se iniciam com as jornadas de junho, numa cooptação dos símbolos nacionais que espetaculariza a cena política e propõe uma dada ideologia política não apenas como única saída possível aos 
problemas do país, mas também como desejo uníssono e inequívoco da população brasileira, e por isso mesmo metonímia de sua identidade.

Ainda em 2018, mas já no decorrer da campanha presidencial, esse tensionamento político em torno da bandeira brasileira torna-se ainda mais conflituoso quando, já no segundo turno, Fernando Haddad - candidato à presidência pelo Partido dos Trabalhadores - passa a fazer uso do verde e amarelo em seu material de campanha, o que foi recebido com críticas por parte de organizações como o Vem pra rua e o Movimento Brasil Livre. Este último, em 21 de outubro de 2018, publica o seguinte enunciado em seu perfil:

Figura 4- Movimento Brasil Livre 2018

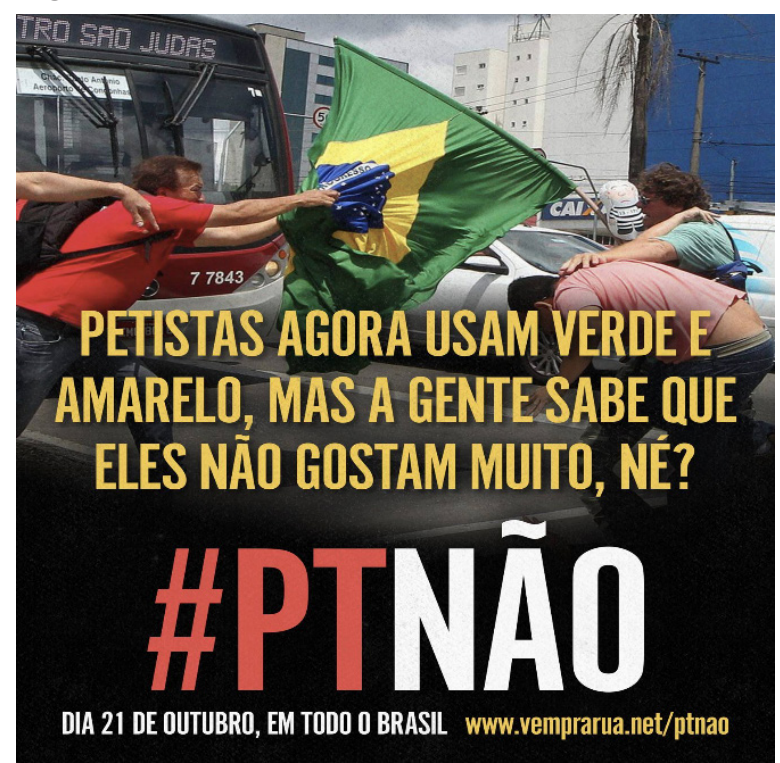

Fonte: Facebook Vem pra rua.

O enunciado ${ }^{8}$ pode ser dividido em duas partes: na parte superior, duas pessoas que carregam a bandeira brasileira são surpreendidas - e aparentemente têm sua integridade física atingida por uma terceira pessoa que, com uma camisa vermelha, tenta usurpar o artefato de modo violento. O modo de apresentação da bandeira - que não flameja, mas aparece como se fora seu último instante antes de rasgar - é uma metonímia da disputa travada entre forças políticas em torno do símbolo nacional. As condições de produção desse enunciado flagram o momento em que o então candidato a Presidente Fernando Haddad (PT), diante desse cenário, encampa o retorno do uso do verde e amarelo por parte da esquerda, numa indicação de que as cores 
V. $11(2)$

1-21

maio-ago

2021

nacionais não são propriedade de grupos isolados. É essa tentativa de reavê-las (e, consequentemente, de inserir o discurso da esquerda também em uma perspectiva daquilo que é tido como patriótico), que é enunciada pelo Movimento Brasil Livre como uma extorsão: trata-se, pelo enunciado, de um apoderamento forçado, o que seria confirmado, ainda, pela materialidade linguística nele impressa.

Na parte inferior, um fundo preto torna visível a hashtag "\#PTNÃO" e a convocação para uma manifestação que aconteceria "em todo o Brasil". Ao centro do enunciado, afirma-se: "Petistas agora usam verde e amarelo, mas a gente sabe que eles não gostam muito, né?". Com essa materialidade, têm-se: i) a nomeação dos "petistas" como sendo o grupo adversário à homogeneização (política e identitária) construída discursivamente em torno da bandeira (grupo com quem, àquela altura, Jair Bolsonaro disputava diretamente a presidência e que, até este momento, sequer aparecia nos enunciados); ii) a indicação, com o advérbio de tempo "agora", de que, anteriormente, esse grupo não fazia uso das cores nacionais e, consequentemente, não adotava um discurso nacionalista, fazendo-o "agora" apenas por interesses políticos; iii) e, por fim, a reativação daquilo que Bauman (2005, p. 28) entende como sendo a naturalização do "pertencer-por-nascimento", que "objetivava o direito monopolista de traçar a fronteira entre 'nós' e 'eles"), aqui materializada com as expressões "a gente" e "eles" (o que exclui os "petistas" da construção de uma identidade nacional; os "petistas" são os outros, são a alteridade do discurso homogeneizante promovido pelo Movimento Brasil Livre).

O efeito de sentido produzido, assim, é de que existe um grupo contrário ao próprio país - na medida em que negligencia suas cores, sua bandeira e seu consonante desejo político -, e do qual é preciso resguardar o Brasil, principalmente pelo fato de que, "agora", esse mesmo grupo tenta, a olhos vistos, como na fotografia, apropriarse violentamente da bandeira nacional e, portanto, do país. Assim, se, a princípio, a bandeira enquanto artefato identitário se propõe a ser uma metonímia da nação, atualmente ela é signo justamente das rupturas que se deram a ver nos últimos anos em terras brasileiras, tanto naquilo que concerne à identidade nacional, quanto naquilo que diz respeito ao cenário político. 


\section{Considerações finais: "Devolvam nossa bandeira"}

Este artigo teve por objetivo problematizar a bandeira brasileira enquanto enunciado que narra uma comunidade simbólica na mesma medida em que se apresenta enquanto signo de sua ruptura. Para tanto, a partir de uma análise arqueológica, tal como proposta por Foucault (2010a; 2010b), procedeu-se à análise: das formas de dizibilidade da bandeira nacional em 1822, com a bandeira do Reino de Brasil; das formas de conservação com o estandarte imperial e com a própria bandeira brasileira, tal como hoje a conhecemos, instituída em 1889; iii) das formas de memória durante o regime militar, com um vasto apelo publicitário que acabou por popularizar o símbolo nacional no cenário esportivo; iv) das formas de reativação que hoje se dão a ver, mediante sua reiterada emergência em enunciados do campo político; v) e das formas de apropriação por parte de uma dada classe política, para a qual urge o apossamento da bandeira como metonímia de um país coeso e uníssono em seu entendimento partidário.

Apontamos, por fim, para as relações de poder que perpassam, ainda hoje, a luta pela bandeira, pela identidade nacional, bem como sua cooptação pela cena política que tenta fazer confundir a identidade nacional com uma dada ideologia partidária. Um exemplo dessa cooptação é o enunciado produzido por Jair Bolsonaro quando da sua posse como $38^{\circ}$ Presidente do país, em janeiro de 2019. Brandindo uma bandeira, o então Presidente afirma: "Esta é a nossa bandeira, que jamais será vermelha, só será vermelha se for do nosso sangue derramado para a manter verde e amarela" 9 . Esse enunciado era o indicativo de que o discurso do governo trabalharia na manutenção daqueles já produzidos desde 2013 e insistentemente reiterados durante a campanha eleitoral: o discurso que desloca a bandeira brasileira de seu sentido identitário para o seu sentido político, o discurso que reconhece os "petistas" como empecilho ao sentido homogeneizante que se tenta imprimir aos partidos conservadores.

Ao mesmo tempo, já se percebe a atuação mais veemente dos partidos que, diante de um "sequestro" articulado e construído desde 2013, restaram a sós com as cores de seus partidos, à margem daquelas nacionalistas. Um exemplo dessa retomada e desse desejo

\footnotetext{
9 Posse de Bolsonaro é marcada por mal-estar com jornalistas. Disponível em: https://www. cartacapital.com.br/politica/posse-de-bolsonaro-e-marcada-por-mal-estar-comjornalistas/. Acesso em: 25 jul. 2020.
} 
V. $11(2)$

1-21

maio-ago

2021

de reapropriação do discurso nacionalista é a campanha - lançada em julho de 2020 - intitulada "Devolvam nossa bandeira"10, em cujo vídeo - que foi amplamente divulgado pela cena política da oposição -, acompanhado de imagens de manifestações em verde e amarelo, ouve-se: "E de repente roubaram as nossas cores, os nossos símbolos, a nossa bandeira. O que era marca de glórias e orgulho, virou a imagem do autoritarismo, da intolerância, do desrespeito, da mentira, da grosseria". Por um lado, o vídeo retoma a espessura histórica das cores nacionais, instituídas para marcar a glória e o orgulho da nação - "a perpetuidade e integridade da patria", conforme Decreto de 1889 (BRASIL, 1889). Por outro, discursiviza o grupo político a quem se dirige, caracterizado pelo "autoritarismo", pela "intolerância", pelo "desrespeito", pela "mentira" e pela "grosseria". Mais à frente, ouvese: "Queremos de volta o que é nosso, queremos voltar a vestir o verde e amarelo para representar a verdadeira bandeira brasileira: a bandeira da paz, da saúde, da vida, a bandeira da democracia". Aqui, ao tempo em que se exige um recuo no roubo dos símbolos nacionais, sinaliza-se a descrição que discursiviza o próprio grupo responsável pela campanha, que se demonstra responsável pela promoção da "paz", da "saúde", da "vida", da "democracia". Seria essa, segundo o vídeo, a "verdadeira bandeira" brasileira.

É à espera dela - da "verdadeira bandeira" - que o Brasil permanece, a despeito das relações de poder e dos interesses escusos que a atravessam.

\section{Referências}

BAUMAN, Zygmunt. Identidade: entrevista a Benedetto Vecchi. Rio de Janeiro: Zahar, 2005.

BRASIL. Decreto de 18 de setembro de 1822 (1822a). Determina o tope nacional Braziliense, e a legenda dos patriotas do Brazil. Disponível em: https://www. camara.leg.br/internet/infdoc/conteudo/colecoes/legislacao/Legimp-F_16. pdf. Acesso em 21 jul. 2020.

BRASIL. Decreto de 18 de setembro de 1822 (1822b). Dá ao Brazil um escudo de armas. Disponível em: https://www.camara.leg.br/internet/infdoc/conteudo/ colecoes/legislacao/Legimp-F_16.pdf. Acesso em 21 jul. 2020.

BRASIL. Decreto no 4, de 19 de novembro de 1889. Estabelece os distinctivos

${ }^{10}$ VÍDEO: Campanha manda que bolsonaristas "devolvam a nossa bandeira". Disponível em: https:// www.diariodocentrodomundo.com.br/essencial/video-campanha-manda-que-bolsonaristasdevolvam-a-nossa-bandeira/. Acesso em: 25 jul. 2020. 
da bandeira e das armas nacionaes, e dos sellos e sinetes da Republica. Diário Oficial da União, seção 1, p. 1, 19 nov. 1889. Disponível em: https://www2. camara.leg.br/legin/fed/decret/1824-1899/decreto-4-19-novembro-1889487510-publicacaooriginal-1-pe.html. Acesso em: 18 jul. 2020.

BRASIL. Lei no 5.700, de 01 de setembro de 1971. Dispõe sobre a forma e a apresentação dos Símbolos Nacionais, e dá outras providências. Diário Oficial da União, 01 set. 1971. Disponível em: http://www.planalto.gov.br/ccivil_03/ leis/15700.htm. Acesso em: 21 jul. 2020.

ESTAÇÃO. Fiesp está proibida de exibir bandeira do Brasil em telão na avenida Paulista. Estação, 18 jul. 2016. Disponível em: https://www.jornalestacao. com.br/2016/07/18/fiesp-esta-proibida-de-exibir-bandeira-do-brasil-emtelao-na-avenida-paulista/. Acesso em: 05 maio 2021.

FOUCAULT, Michel. Dits et écrits (Tome 2-1976-1988). Paris, Gallimard, 2001.

FOUCAULT, Michel. A arqueologia do saber. Rio de Janeiro: Forense Universitária, 2010a.

FOUCAULT, Michel. Resposta a uma questão. In: FOUCAULT, Michel. Repensar a política. Coleção ditos e escritos VI. Organização de Manoel Barros da Motta. Trad. Ana Lúcia Paranhos Pessoa. Rio de Janeiro: Forense Universitária, 2010b. p. $1-25$.

GUEDES, Simoni Lahud; SILVA, Edison Márcio de Almeida da. O segundo sequestro do verde e amarelo: futebol, política e símbolos nacionais. Cuadernos de Aletheia, Buenos Aires, n. 3, p. 73-89, 2019. Disponível em: http://www. memoria.fahce.unlp.edu.ar/art_revistas/pr.9691/pr.9691.pdf. Acesso em: 05 jun. 2020.

HALL, Stuart. A identidade cultural na pós-modernidade. Trad. Tomaz Tadeu da Silva e Guacira Lopes Louro. 10.ed. Rio de Janeiro: DP\&A, 2006.

LUZ, Milton. A história dos símbolos nacionais: a bandeira, o brasão, o selo, o hino. Brasília: Senado Federal, Secretaria Especial de Editoração e Publicações, 2005. Disponível em: https://www2.senado.leg.br/bdsf/bitstream/handle/ id/1099/729330.pdf? sequence=4. Acesso em: 21 jul. 2020.

O POVO ONLINE. Designer cria camisa vermelha da Seleção Brasileira para pessoas de esquerda. O povo online, 11 abr. 2018. Disponível em: https://www. opovo.com.br/esportes/futebol/2018/04/designer-cria-camisa-vermelhada-selecao-brasileira-para-pessoas-de-es.html. Acesso em: 05 maio 2021.

PINTO, Céli Regina Jardim. A trajetória discursiva das manifestações de rua no Brasil (2013-2015). Lua Nova, São Paulo, n. 100, p. 119-153, 2017. Disponível em: https://www.scielo.br/pdf/ln/n100/1807-0175-ln-100-00119.pdf. Acesso em: 18 jul. 2020.

PIRES, Breiller. Camisa da seleção, o símbolo contaminado por rixas ideológicas e as negociatas dos cartolas. El País Brasil, 17 jun. 2018. Disponível em: https://brasil.elpais.com/brasil/2018/06/16/deportes/1529108134_704637. html. Acesso em: 05 maio 2021.

SOUSA SANTOS, Boaventura. Modernidade, identidade e cultura de fronteira. Tempo Social, São Paulo, V. 5, n. 1-2, p. 31-52. 1993. 